\title{
BORDADURA DE POMAR E FLUTUAÇÃO POPULACIONAL DE Anastrepha fraterculus (DIPTERA: TEPHRITIDAE) EM SISTEMA ORGÂNICO DE PRODUÇÃO DE MAÇÃ
}

\section{BORDER OF ORCHARD AND POPULATION FLUCTUATION OF Anastrepha fraterculus (DIPTERA: TEPHRITIDAE) UNDER ORGANIC PRODUCTION SYSTEM OF APPLE}

\author{
Rosangela TEIXEIRA ${ }^{1}$ \\ Mari Inês Carissimi BOFF ${ }^{2}$ \\ Luiz Gonzaga RIBEIRO ${ }^{3}$ \\ Pedro BOFF ${ }^{4}$
}

\begin{abstract}
RESUMO
Este trabalho teve como objetivo avaliar a influência da flora no entorno do pomar de macieiras conduzidas sob sistemas orgânicos na flutuação populacional de Anastrepha fraterculus. Os estudos foram realizados durante as safras 2007/08 e 2008/09 em três pomares no município de São Joaquim, SC, sendo dois comerciais e um experimental da EpagriSão Joaquim. A área média de cada pomar era de 1,5 hectares, cultivados com as variedades Gala e suas mutantes, Fuji e suas mutantes, Catarina e Joaquina, cujo entorno apresentava composição florística diferenciada. Para o monitoramento da mosca-das-frutas foram utilizadas armadilhas modelo McPhail $\circledast$ com fundo amarelo, contendo suco de uva a $25 \%$. Quatro armadilhas por pomar foram instaladas a uma altura média de 1,8 metros da superfície do solo, nos ramos externos da terceira planta da primeira fila no sentido periferia centro do pomar. A avaliação de captura foi realizada a cada sete dias, ocasião em que a solução atrativa era substituída. O pico populacional foi maior no pomar A, local considerado desfavorável à presença da mosca, pela composição florística encontrada em seu entorno. A proximidade de pomares de outras frutíferas pode ser a razão para este aumento de população de $A$. fraterculus.
\end{abstract}

Palavras-chave: Diversidade vegetal, Hospedeiros primários, Mosca-das-frutas.

\section{ABSTRACT}

The objective of this research was to evaluate the influence of the flora surrounding apple orchards on the population fluctuation of Anastrepha fraterculus. The experiments were conducted in three organic apple orchards, being one experimental belong to EPAGRI and two commercial orchards located in the region of São Joaquim, Santa Catarina State. The study was carried out during 2007/08 and 2008/09 crop seasons. Each orchard had an area of 1.5 hectare cultivated with cv. Gala and its mutants, Fuji and its mutants, Catarina, and Joaquina. McPhail plastic traps with yellow background containing grape juice at $25 \%$ were used for monitoring the fruit fly. Four traps per orchard were placed at $1.8 \mathrm{~m}$ high from soil surface, on the external branches of the third plant of the first row from the periphery to the centre of each orchard. The fruit fly evaluations were done in each seven days, at the occasion when the attractive solution was renewed. The population peak was the highest in the orchard, that conditions were considered unfavourable to fruit fly occurrence. This was probably due to flora composition surrounding the orchard. The proximity of other fruit orchards may also be the reason for this increase in population of $A$. fraterculus.

Key words: Plant diversity, Primary hosts, Fruit fly.

\footnotetext{
${ }^{1}$ Acadêmica do Curso de Mestrado em Produção Vegetal da Universidade do Estado de Santa Catarina (UDESC). Centro de Ciências Agroveterinárias (CAV).

${ }^{2}$ Ph.D., Professora do Departamento de Agronomia, CAV/UDESC. Av. Luiz de Camões, 2090, Bairro Conta Dinheiro, CEP 88520-000, Lages, SC, Brasil. E-mail: 2micb@cav.udesc.br

${ }_{3}$ Pesquisador, Pesquisador da Empresa de Pesquisa Agropecuária e Extensão Rural de Santa Catarina (EPAGRI), Estação Experimental de São Joaquim.SC

${ }^{4}$ PQ-CNPq Pesquisador da Empresa de pesquisa Agropecuária e Extensão Rural de Santa Catarina (EPAGRI), Estação Experimental de Lages.
} 
TEIXEIRA, R. et al. Bordadura de pomar...

\section{INTRODUÇÃO}

A mosca-das-frutas é a mais frequente praga em fruteiras no Brasil. No estado de Santa Catarina, estudos mostraram que 70 das espécies assinaladas, tem ocorrência no estado (Garcia et al., 2002). Destas o gênero Anastrepha, é o mais abundante, sendo relatadas nove espécies pertencentes a este gênero (Alberti et al., 2009). Na qual a espécie Anastrepha fraterculus (Wiedemann, 1830) (Diptera: Tethritidae) é considerada a espécie mais abundante (Garcia et al., 2003). Esta é multivoltina e apresenta mais de seis gerações por ano (Machado et al., 2000). Além disso, é polífaga, sendo conhecidas como hospedeiros principais plantas das famílias Anacardiaceae, Myrtaceae, Passifloraceae e Sapotaceae (Zucchi, 2008).

O conhecimento da dinâmica populacional e a época de maior ocorrência deste inseto é um importante fator para o estabelecimento de estratégias de manejo, principalmente, em pomares sob sistemas orgânicos de produção (Telles \&Silva, 2005). A flutuação populacional da $A$. fraterculus varia dependendo do período do ano, local e disponibilidade de frutos hospedeiros, podendo apresentar irregularidades. Segundo Aluja (1994), os fatores que mais influenciam as variações populacionais da mosca-das-frutas são a disponibilidade de hospedeiros primários e as variações climáticas. $\mathrm{O}$ condicionamento interno de um pomar pode ser fortemente influenciado pelas condições externas, presentes no entorno, principalmente se neste ambiente extra-pomar inclui áreas ribeirinhas e habitat de florestas (Miliczky \& Horton, 2005). Isto porque, ocorre troca entre os organismos que habitam estes ambientes onde o pomar é frequentemente visitado por espécies de insetos que vivem nas florestas do entorno, enquanto que espécies predominantes no monocultivo também exploram as bordas. Esta troca pode favorecer o desenvolvimento e a permanência do inseto-praga, já que muitas espécies utilizam este refugio como sendo um local para acasalamento e refugio para muda e hibernação (Letourneau, 1998). Em estruturas de comunidades orgânicas ocorrem uma maior diversidade de herbívoros e parasitóides (Letourneau \& Goudstein, 2001). Assim a escolha da área para implantação do pomar pode ser de grande importância. Quando este apresenta poucas condições favoráveis, o agricultor pode ter menor custo no manejo da moscadas-frutas.

O objetivo deste trabalho foi avaliar a influência da flora no entorno de pomares de macieira conduzidos sob sistema orgânico de produção sobre a flutuação populacional de Anastrepha fraterculus.

\section{MATERIAL E MÉTODOS}

O estudo foi realizado durante as safras de 2007/08 e 2008/09 em três pomares de macieira localizados no município de São Joaquim, SC, conduzidos em sistema orgânico de produção.

O pomar A possuía área cultivada de 1,2 ha, sendo proprietário o agricultor Velocino Bolzani Neto, localizado a 1.142 metros de altitude, $28^{\circ} 12^{\prime}$ sul, $50^{\circ} 03^{\prime}$ oeste e $25 \mathrm{~km}$ distante da cidade de São Joaquim, SC. O pomar era formado com espaçamento de $2 \times 5 \mathrm{~m}$ e fileiras intercaladas de plantas de macieiras 'Fuji Suprema' e 'Imperial Gala' com 10 anos de idade em porta-enxerto 'Marubakaido' com filtro EM-9, entre plantas. A vegetação no entorno do pomar era de fisionomia Floresta Ombrófila Mista, característica da região com remanescentes de Campos de Altitude e Floresta de Araucária. Em distância de mil metros, em linha reta, estavam implantados pomares de macieiras das cultivares 'Catarina' e 'Joaquina', também conduzidos sob o sistema orgânico de produção e em distâncias maiores (não analisadas), pomares manejados em sistema integrado.

O pomar $\mathrm{B}$, com área cultivada de 1,3 ha, pertencente a agricultora Beatriz Reichert, estava localizado na altitude de 1.228 metros, $28^{\circ} 80^{\prime}$ sul, $57^{\circ} 54^{\prime}$ oeste e distante $22 \mathrm{~km}$ da cidade de São Joaquim, SC. O Pomar era composto por fileiras intercaladas de macieiras 'Fuji Suprema' e 'Gala Stander' com 12 anos de idade em porta-enxerto 'Marubakaido' com filtro EM-9, no espaçamento de $2 \times 5 \mathrm{~m}$. O entorno do pomar era de composição florística característica da Floresta Ombrófila Mista e Mata de Araucária. Próximo do pomar havia cultivo de goiabeira serrana (Acca sellowiana) em área de 0,2 ha e plantas de pessegueiro. Em ambas as safras, $2007 / 08$ e 2008/09, todos os frutos deste pomar foram ensacados com sacos de plástico microperfurados. Na safra 2007/08, o ensacamento foi realizado em novembro e na safra 2008/09 o ensacamento foi realizado outubro.

O pomar $C$, com área cultivada de 0,6 ha localizava-se na área da Estação Experimental da Epagri São Joaquim, SC, na altitude de 1.415 metros, $16^{\circ} 53^{\prime}$ sul e $56^{\circ} 25^{\prime}$ oeste. O Pomar era composto por filas intercaladas de maçãs das variedades 'Catarina' e 'Joaquina' com seis anos de idade. O porta-enxerto utilizado era o EM-9 e o espaçamento entre as plantas de $1 \times 4 \mathrm{~m}$, entre plantas. A vegetação característica no entorno deste pomar era de campo aberto com cordão quebra-vento na posição leste-oeste formado por plantas de Pinus sp. Próximo ao pomar, na distância de 200 e 500 metros, havia pomares de pera e goiabeira-serrana, respectivamente, conduzidos em sistema integrado de produção.

\section{Monitoramento da mosca-das-frutas}

Em cada pomar foram instaladas quatro armadilhas do modelo McPhail $\AA$ com fundo amarelo, contendo suco de uva a $25 \%$. As armadilhas foram dispostas nas plantas de macieira da primeira fila, localizadas na periferia do pomar e distribuídas em pontos considerados de entrada da mosca, sendo instaladas a uma altura média de 1,8 metros da superfície do solo, nos ramos externo das plantas. $\mathrm{Na}$ safra 2007/08, as armadilhas foram instaladas no dia 20 de novembro de 2007, permanecendo no campo até o dia 04 de março de 2008. Na safra 
TEIXEIRA, R. et al. Bordadura de pomar...

$2008 / 09$, as armadilhas foram instaladas no dia 10 de novembro de 2008 e permaneceram até dia 23 de fevereiro de 2009 . A solução atrativa era renovada semanalmente e os adultos capturados da mosca-das-frutas eram retirados das armadilhas, feita coagem em peneira de malha fina e acondicionados em frascos plásticos, contendo álcool $70 \%$. No Laboratório de Entomologia da Estação Experimental da Epagri, São Joaquim-SC, os insetos capturados foram separados, contados e sexados. Após, os adultos da mosca-das-frutas eram acondicionados em frascos plásticos individuais, contendo álcool $70 \%$, para posterior confirmação da espécie. Para tanto, utilizou-se chave de identificação organizada por Zucchi (2000). O cálculo da razão sexual foi feito pela divisão do número de fêmeas com o total de adultos capturados.

\section{Avaliação da diversidade vegetal no entorno do} pomar

Em cada pomar foi realizado levantamento sistemático da vegetação do entorno, utilizando o método de ponto quadrante (Cottam \& Curtis 1956), com coleta de estruturas de plantas durante o mês de maio de 2008. Foram demarcados quatro pontos de amostragem estabelecidos em cada lado do pomar. O levantamento teve abrangência de 2 metros de largura e 50 metros de comprimento, partindo da primeira planta na bordadura do pomar em cada ponto amostrado, sendo a distância entre um ponto e outro de 50 metros. Em cada ponto amostral foram realizadas coletas de partes aéreas (folhas, frutos e/ou flores) das espécies arbustivas e arbóreas encontradas. As espécies coletadas foram prensadas a campo e levadas para a Estação Experimental da Epagri de Lages, SC, onde foram herborizados. A identificação das espécies seguiu os padrões da taxonomia com base em caracteres morfo- lógicos das espécies conforme Harri (2008).

Dados climáticos de temperatura máxima, média e mínima, umidade relativa do ar e intensidade de chuva foram obtidos da Estação Meteorológica da Epagri - São Joaquim. Os pomares localizados nas propriedades de Velocino Bolzani e Beatriz Reichert estavam a distância de 25 e $22 \mathrm{~km}$ da estação meteorológica respectivamente. O pomar da Est. Exp. de São Joaquim localizava-se a $1 \mathrm{~km}$ do posto de coleta de dados.

Os dados do levantamento das moscas foram expressos pelo valor acumulado de captura nas armadilhas e submetidos a análise de variância (ANOVA) e as médias comparadas pelo teste de Tukey $(p<0,05)$, com o auxílio do programa SAS (Sas Institute, 2002).

\section{RESULTADOS E DISCUSSÃO}

O número total de adultos da mosca-dasfrutas capturados através de armadilhas nos três pomares nas safras 2007/08 e 2008/09 foi de 54 e 1.721 , respectivamente (Tabela 1). Todos os exemplares da mosca-das-frutas capturados pertenciam à espécie Anastrepha fraterculus. Isto concorda com os resultados obtidos por Salles (1995) e Zilli \& Garcia (2010), os quais afirmam ser a espécie $A$. fraterculus a mais abundante no sul do Brasil. O número de fêmeas capturadas nas armadilhas com suco de uva foi maior do que o número de machos nas duas safras para os três pomares (Tabela 1). Resultados semelhantes foram obtidos por Scoz et al. (2006) os quais, trabalhando com $A$. fraterculus em pêssego capturaram 1,5 vezes mais fêmeas do que machos em todos as amostragens.

Tabela 1- Número de adultos de Anastrepha fraterculus capturados em armadilhas McPhail囚, contendo solução de suco de uva a $25 \%$ em pomares orgânicos de macieira, São Joaquim, SC.

\begin{tabular}{|c|c|c|c|c|c|c|c|c|}
\hline \multirow{3}{*}{ Pomar } & \multicolumn{4}{|c|}{$\begin{array}{l}\text { Captura cumulativa* } \\
\text { (N/armadilha) }\end{array}$} & \multicolumn{2}{|c|}{$\begin{array}{c}\text { Captura diária } \\
\text { ( } \mathrm{N} \text { total/armadilha) }\end{array}$} & \multicolumn{2}{|c|}{ Razão sexual** } \\
\hline & \multicolumn{2}{|c|}{$2007 / 08$} & \multicolumn{2}{|c|}{$2008 / 09$} & \multirow[t]{2}{*}{$2007 / 08$} & \multirow[t]{2}{*}{$2008 / 09$} & \multirow[t]{2}{*}{$2007 / 08$} & \multirow[t]{2}{*}{$2008 / 09$} \\
\hline & Machos & Fêmeas & Machos & Fêmeas & & & & \\
\hline$A$ & $12 a$ & $22 a$ & $443 a$ & $914 a$ & $0,07 a$ & $2,8 a$ & 0,64 & 0,67 \\
\hline B & $3 b$ & $12 b$ & $110 \mathrm{~b}$ & $237 b$ & $0,03 b$ & $0,7 \mathrm{~b}$ & 0,83 & 0,68 \\
\hline C & $2 b$ & $3 c$ & $13 c$ & $64 c$ & $0,01 b$ & $0,15 b$ & 0,60 & 0,83 \\
\hline $\mathrm{CV}(\%)$ & 22,3 & 38,4 & 29,3 & 24,5 & 12.5 & 19.3 & 0,00 & 0,00 \\
\hline
\end{tabular}

* Dados são medias de 4 armadilhas;

** Razão sexual obtida pela relação do numero de fêmeas e o total de mosca-das-frutas capturadas

O pico populacional de $A$. fraterculus, na safra 2007/08, ocorreu no mês de janeiro em todos os pomares (Figura 1), enquanto que na safra 2008/09 ocorreu no mês de dezembro (Figura 2). Em pomares de citros Chiaradia et al. (2004) observaram pico de população a partir do mês de janeiro. Por outro lado, em pomares de pêssego o pico populacional observado foi nos meses de outubro e novembro em duas safras avaliadas (Harter et al., 2010). Variação na flutuação populacional de $A$. fraterculus ocorre devido a mudanças de temperaturas de cada safra, variações de culturas, localidades, bem como alternâncias de frutificação dos hospedeiros para épocas mais tardias ou mais precoces (Garcia et al., 2003). 
TEIXEIRA, R. et al. Bordadura de pomar...

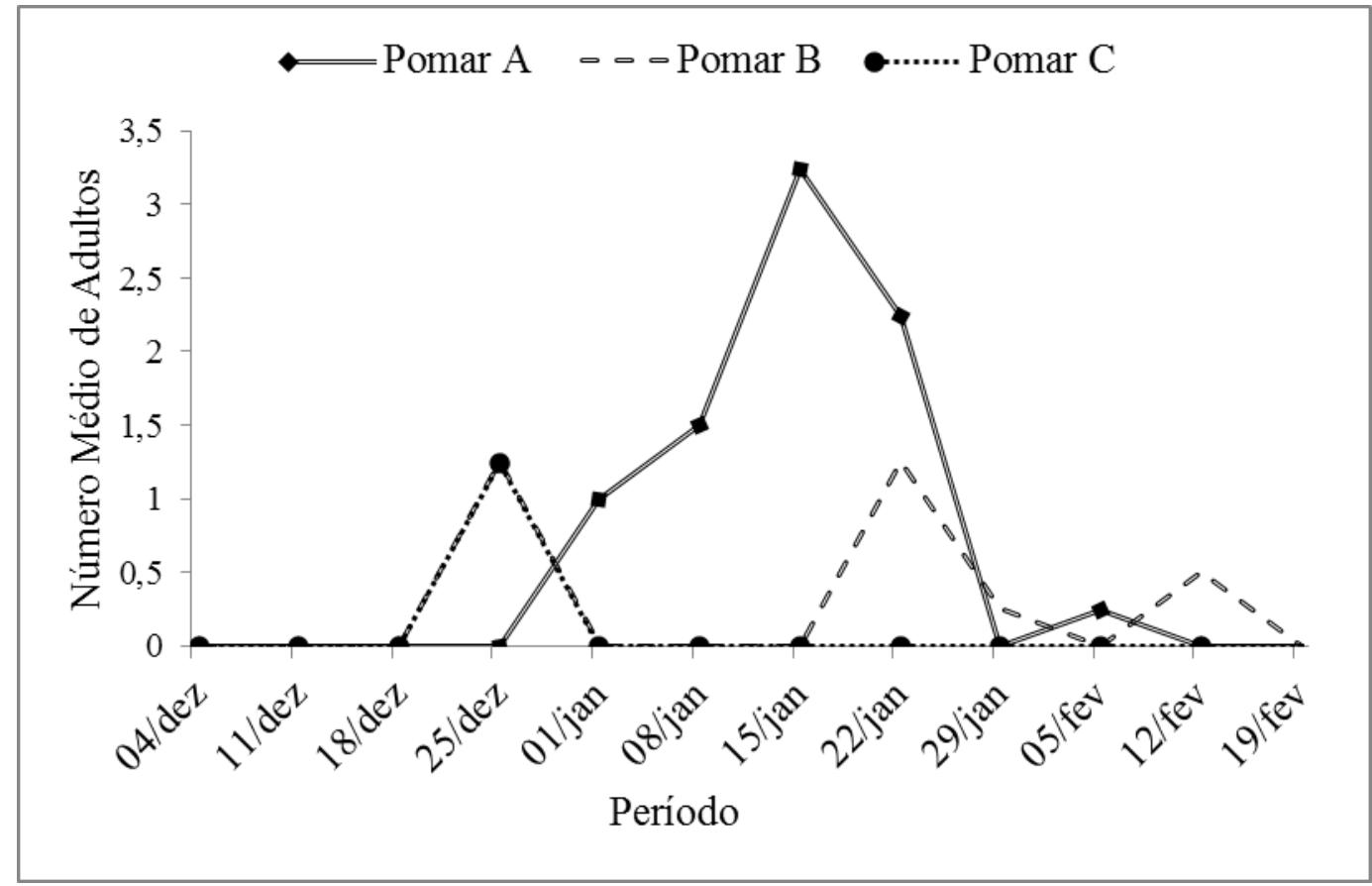

Figura 1- Número médio de adultos de Anastrepha fraterculus capturados em armadilhas McPhail iscadas com suco de uva a $25 \%$, em pomares de macieira conduzidos sob o sistema orgânico. Safra 2007/08, São Joaquim, SC.

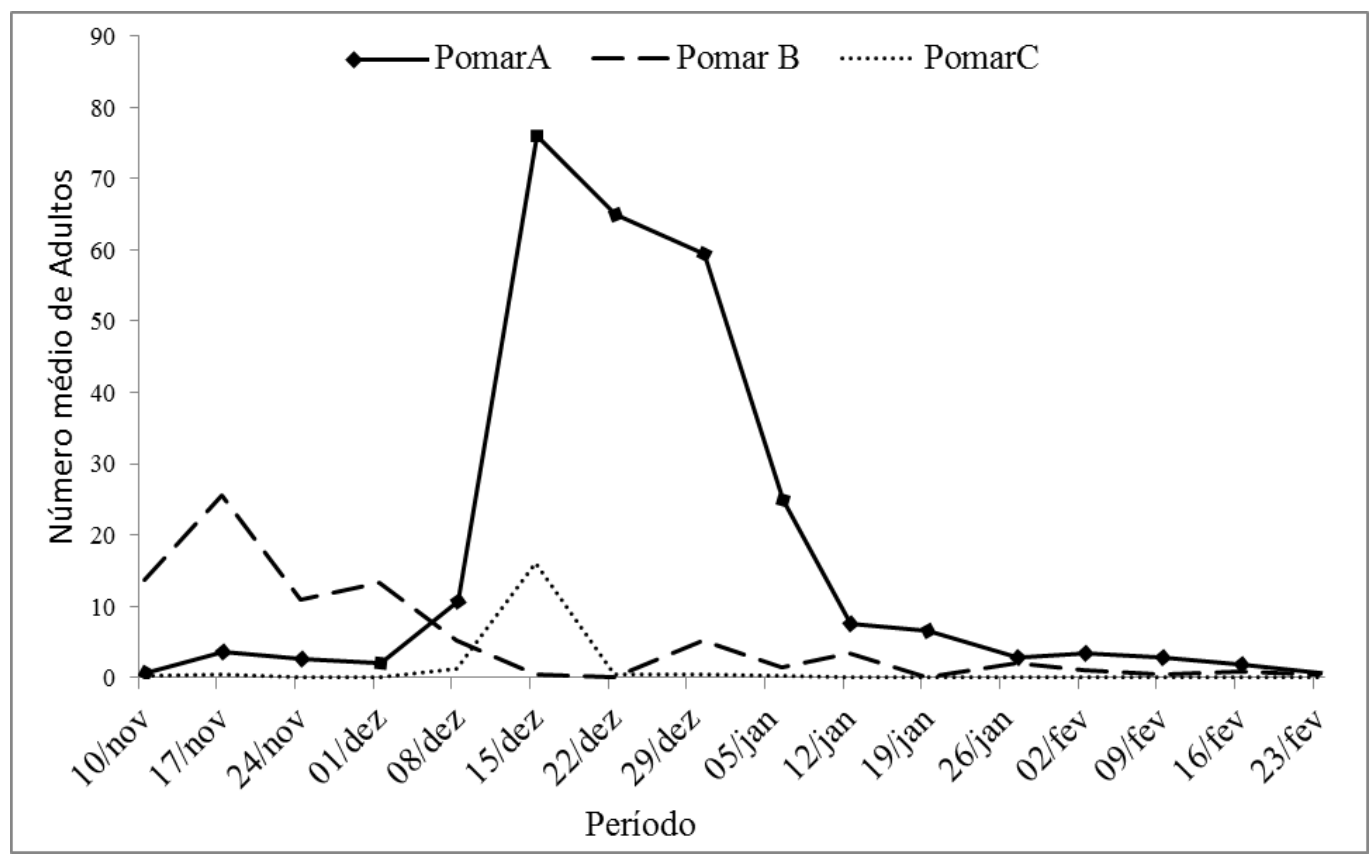

Figura 2- Número médio de adultos de Anastrepha fraterculus capturados em armadilhas McPhail iscadas com suco de uva a $25 \%$, em pomares de macieira conduzidos sob o sistema orgânico. Safra 2008/09, São Joaquim, SC. 
TEIXEIRA, R. et al. Bordadura de pomar...

Dados meteorológicos no período entre novembro de 2007 a março de 2008 demonstram que a temperatura média diária foi de 10,74 e $19^{\circ} \mathrm{C}$ e a umidade relativa do ar variaram entre 71 a $74,8 \%$, com precipitação acumulada de $669,5 \mathrm{~mm}$. No período de novembro de 2008 a março de 2009, a temperatura média diária foi de 12 a $21,82{ }^{\circ} \mathrm{C}$ e a umidade relativa de 81,2 a $83,8 \%$, com precipitação acumulada de $1.152,8 \mathrm{~mm}$. Telles \& Silva (2005) relatam que a flutuação da mosca-das-frutas varia em função principalmente de temperatura e pluviosidade. $\mathrm{O}$ aumento de dois graus na temperatura, bem como a variação da umidade e precipitação, podendo ser a razão principal da alta flutuação na segunda safra.

O pomar que apresentou a maior população de $A$. fraterculus foi o pomar A (Tabela 1), totalizando 34 adultos na safra 2007/08 e 1.357 adultos, na safra $2008 / 09$. O número de mosca/armadilha/ dia (MAD) na safra $2007 / 08$ foi de 0,07 e na safra 2008/09 foi de 2,8 (Tabela 2). Em contraste ao número de moscas, o pomar A não dispõe, ao seu redor, espécies hospedeiros primários da moscadas-frutas, enquanto que nos pomares $\mathrm{B}$ e $\mathrm{C}$, o número total foi de 15 e 5 , respectivamente, com correspondente número MAD de 0,03 e 0,01. Na safra 2008/09, obteve-se maior número de captura do que em 2007/08, com 347 adultos para o pomar B e 77 para o pomar C, e MAD de 0,7 e 0,15, respectivamente, sendo sempre inferior a captura do pomar A (Tabela 2). Portanto, faz-se necessário aprofundar estudos sobre estruturas e funcionamento das comunidades para poder entender estas relações entre praga/hospedeiro e assim obter correlações da presença ou ausência no pomar e o respectivo manejo cultural (Southwood, 1995).

Tabela 2 - Espécies vegetais arbustivas e arbóreas presentes no entorno de pomares A e B de macieira, São Joaquim, SC.

\begin{tabular}{|c|c|c|c|}
\hline Família & Nome científico & Nome comum & Hospedeiro \\
\hline \multicolumn{4}{|c|}{ Pomar A } \\
\hline Araucareaceae & Araucaria angustifolia & Pinheiro-brasileiro & Não hospedeiro \\
\hline Sapindaceae & Dodonea viscosa & Vassourão & Não hospedeiro \\
\hline Asteraceae & $\begin{array}{l}\text { Bacharis trimera, } \\
\text { Bacharis uncinella }\end{array}$ & $\begin{array}{l}\text { Carqueja-do-mato } \\
\text { Vassoura-lageana }\end{array}$ & $\begin{array}{l}\text { Não hospedeiro } \\
\text { Não hospedeiro }\end{array}$ \\
\hline \multicolumn{4}{|c|}{ Pomar B } \\
\hline Anonaceae & Rollinia sylvatica & Araticum-do-mato & Alternativo \\
\hline Araucareaceae & Araucaria angustifolia & Pinheiro-brasileiro & Não hospedeiro \\
\hline Anarcadiaceae & $\begin{array}{l}\text { Acca sellowiana } \\
\text { Psidium cottleianum } \\
\text { Campomanesia eugenioides } \\
\text { Blephorocolyx salicifolius } \\
\text { Lithraca brasiliensis }\end{array}$ & $\begin{array}{l}\text { Goiabeira-serrana } \\
\text { Araçá } \\
\text { Gabirobeira } \\
\text { Perta-guela } \\
\text { Aroeira (bugreiro) }\end{array}$ & $\begin{array}{l}\text { Primário } \\
\text { Primário } \\
\text { Primário } \\
\text { Não hospedeiro } \\
\text { Não hospedeiro }\end{array}$ \\
\hline $\begin{array}{l}\text { Asteraceae } \\
\text { Sapindaceae }\end{array}$ & $\begin{array}{l}\text { Baccharis trimera } \\
\text { Baccharis uncinella } \\
\text { Dodonea viscosa }\end{array}$ & $\begin{array}{l}\text { Carqueja-do-mato } \\
\text { Vassoura-lageana } \\
\text { Vassourão }\end{array}$ & $\begin{array}{l}\text { Não hospedeiro } \\
\text { Não hospedeiro } \\
\text { Não hospedeiro }\end{array}$ \\
\hline Mimosoideae & Mimosa scabrella & Bracatinga & Não hospedeiro \\
\hline Moraceae & Brosemopsis lactescens & Pau-leiteiro & Não hospedeiro \\
\hline Celastreceae & Maytenuz ilicifolia & Espinheira-santa & Não hospedeiro \\
\hline Rosaceae & Rubus sp. & Amora-silvestre & Alternativo \\
\hline \multirow[t]{3}{*}{ Clethroceae } & Clethra scabra & Carne-de-vaca & Não hospedeiro \\
\hline & \multicolumn{3}{|l|}{ Pomar C } \\
\hline & $\begin{array}{l}\text { Pinnus sp } \\
\text { Paspalum sp } \\
\text { Axonopus sp } \\
\end{array}$ & $\begin{array}{l}\text { Pinus } \\
\text { Pastagem } \\
\text { Pastagem } \\
\end{array}$ & $\begin{array}{l}\text { Não hospedeiro } \\
\text { Não hospedeiro } \\
\text { Não hospedeiro }\end{array}$ \\
\hline
\end{tabular}


O pomar B apresentou maior diversidade de espécies hospedeiras nativas com destaque para as espécies das famílias Myrtaceae, Anonaceae e Rosaceae, consideradas hospedeiras primárias de $A$. fraterculus. Estudos relatam que estas famílias são as principais hospedeiras da mosca-das-frutas (Zuchi, 2008). Porém em nosso trabalho observouse que o maior número de espécies hospedeiras presente no pomar B não proporcionou maior captura de mosca, concordando com Garcia \& Corseuil, (1999) que afirmam que além da disponibilidade de hospedeiros alternativos próximos do pomar, outros fatores interferem na dinâmica de flutuação da mosca.

O maior número de mosca-das-frutas coletadas no pomar A pode ser devido a sua proximidade a pomares de macieiras conduzidos no sistema integrado, onde houve aplicação regular de pesticidas. Segundo Carvalho (2005), quando é realizado o controle químico, as moscas-das-frutas se dispersam, na ausência de hospedeiros secundários próximos e tendem a invadir novas áreas do hospedeiro principal. $\mathrm{Na}$ falta de hospedeiros primários, a mosca busca um hospedeiro alternativo, sendo utilizado o hospedeiro secundário. Sugayama et al. (1998) em estudo realizado sobre biologia da $A$. fraterculus, associada a cultivares de maçã, não encontraram restrições comportamentais e fisiológicas para seu desenvolvimento em macieiras. No entanto, dados de coleta de frutos e monitoramento sugerem que as populações de mosca-das-frutas não estão estabelecidas no pomar, mas iniciam a infestação a cada safra. Dessa forma, os hospedeiros nativos atuam como os repositórios nos períodos entressafras.

Em contraste ao pomar A, o pomar B apresentou baixa população da mosca-das-frutas na primeira safra 2007/08, desde o início da instalação das armadilhas (Figura 1). Esse resultado pode estar relacionado ao ensacamento dos frutos realizado a partir dos 40 dias após a plena floração durante as duas safras, dificultando o aumento da progênie no mesmo pomar. De fato, na safra 2008/09 foi observada baixa população e somente a partir do segundo mês de monitoramento, quando não havia frutos para oviposição, ocorrendo então migração ou dispersão dos adultos para outros pomares ou hospedeiros alternativos (Figura 2). Segundo Chiaradia et al. (2004) as moscas-das-frutas têm elevado potencial biótico, além da habilidade de dispersão e adaptação em novos hospedeiros. Apesar do entorno ao pomar B apresentasse frutíferas nativas, hospedeiras do inseto, como a amora, pês- sego e goiabeira-serrana as mesmas não possuíam ainda frutos maduros, o que não atraiu as moscas para a bordadura do pomar.

O pomar C, localizado na Estação Experimental da Epagri, foi aquele que apresentou menor número de moscas (Tabelas 1 e 2). A disponibilidade de hospedeiros no entorno e a localização em altitude de $1.415 \mathrm{~m}$ pode ter influenciado na captura. A bordadura deste pomar era composta por quebra-vento de pinus e relvado. A falta de hospedeiros alternativos, combinado com fatores climáticos encontrados proporcionou a este pomar baixa flutuação da mosca-das-frutas. Pode-se dizer que fatores climáticos restringiram o aumento populacional de moscas no pomar $C$. Entretanto, não se pode afirmar em qual fase de desenvolvimento interferiu, visto que as capturas foram realizadas apenas em caça-moscas com atrativo alimentar. $\mathrm{Na}$ comparação dos três pomares, observa-se que quanto maior a altitude menor o número de insetos capturados, visto que os pomares $A, B$ e $C$ estão localizados a $1.142,1.228$ e $1.415 \mathrm{~m}$, respectivamente.

O local indicado para a instalação de um pomar deve ser aquele que apresenta características desfavoráveis à ocorrência da mosca no estádio de maturação dos frutos, proximidade com outros pomares comerciais e levando-se em conta as espécies hospedeiras, no entorno ao pomar. A reintrodução da mosca-das-frutas no pomar está relacionada a vegetação que compõem a bordadura do pomar, podendo ocorrer re-infestações a cada safra.

\section{CONCLUSÕES}

A presença de espécies vegetais de hospedeiros primários influencia na população de Anastrepha fraterculus em pomares de maçã.

A proximidade do pomar de maçã com pomares de outras frutíferas com uso de pesticidas aumenta a probabilidade de ocorrência da moscadas-frutas em pomares localizado em áreas consideradas desfavoráveis.

\section{AGRADECIMENTOS}

Os autores agradecem aos agricultores Beatriz Reichert e Velocino Bonzani pela disponibilização dos pomares para a realização do trabalho e ao apoio financeiro, FAPESC/MCT/CT-HIDRO/ CNPq através do projeto Rede Guarani/Serra Geral convênio FAPEU/FAPESC 16261/10-2.

\section{REFERENCIAS}

1. ALBERTI, S; GARCIA, M. R. F; BOGUS, M. G. Moscas-das-frutas em pomares de pessegueiro e maracujazeiro, no Município de Iraceminha, Santa Catarina, Brasil. Ciência Rural, Santa Maria. v.35, n.5 p. 1565-1568, 2009

2. ALUJA, M. Bionomics and management of Anastrepha. Revista Entomológica. v. 39, p 155- 178, 1994

3. CARVALHO, R. S. Controle Biológico de Moscas-das-frutas (Tephritidae) no Brasil, p. 375-376. In: POLTRONIERI, L.S, TRINDADE, D.R. \& SANTOS, I.P. Pragas e Doenças de Cultivos Amazônicos. Belém, EMBAPA, 2005

4. COTTAM, G.; CURTIS, J.T. The use of distance measures in phytosociological sampling. Ecology. 37: 451-460. 1956.

5. CHIARADIA, A. L.; MILANEZ, M. J.; DITTRICH, R. Flutuação populacional de mosca-das-frutas em pomares de citros no oeste de Santa Catarina, Brasil. Ciência Rural, Santa Maria, v.34, n.2, p.337-343, 2004. 
TEIXEIRA, R. et al. Bordadura de pomar...

6. GARCIA, F. R. M.; CAMPOS, J. V.; CORSEUIL, E. Flutuação populacional de Anastrepha fraterculus (Wiedemann, 1830) (Diptera: Tephritidae) na Região Oeste de Santa Catarina, Brasil. Revista Brasileira de Entomologia. Curitiba, v.47, p.415420, 2003.

7. GARCIA, F. R. M; CAMPOS, J. V; CORSEUIL, E. Lista documentada das moscas-das-frutas (Diptera, Tephritidae) de Santa Catarina, Brasil. Biociências, v. 10. n.1, p-139-148, 2002.

8. GARCIA, F. R. M.; CORSEUIL, E. Análise faunística de moscas-das-frutas (Diptera, Tephritidae) em pomares de pessegueiro em Porto Alegre, Rio Grande do Sul. Revista Brasileira de Zoologia, Curitiba, v.15, p.1111-1117, 1998.

9. HARRI, L. Árvores brasileiras: Manual de identificação e cultivo de plantas arbóreas nativas do Brasil, v.1 5. ed, Plantarum, 2008, 352p

10. HARTER, R. W; GRÜTZMACHER, D. A; NAVA, E. D; GONÇALVES, S. R; BOTTON, M. Isca tóxica e disrupção sexual no controle da mosca-das-frutas-sul-americana e da mariposa-oriental em pessegueiro. Pesquisa Agropecuária Brasileira. Brasília. v.45. n.3. p.229-235. 2010.

11. LETOURNEAU, D. K; B. GOLDSTEIN, B. Pest damage and arthropod community structure in organic vs. conventional tomato production in California. Journal of applied ecology. University of Califórnia, Santa Cruz. v. 38, p-557-570. 2001.

12. LETOURNEAU, D. K. Conservation biology: lessons for conserving natural enemies. In: BARBOSA, P. (Ed.), Conservation Biological Control. Academic Press, San Diego, p. 9-38. 1998.

13. MACHADO, A. E.; SALLES, L. A. B.; LOECK, A. E. Exigências térmicas de Anastrepha fraterculus (WIED) e estimativa do número de gerações anuais em Pelotas, RS. Anais Sociedade Entomológica do Brasil, Londrina, v.24, p.573-578, 2000.

14. MILICZKY, R. E; HORTON, R. D. Densities of beneficial arthropods within pear and apple orchards affected by distance from adjacent native habitat and association of natural enemies with extra-orchard host plants. Biological Control. v. 33. P249-259. 2005.

15. SALLES, L. A. B. Bioecologia e controle das moscas-das-frutas-sulamericana, Pelotas: EMBRAPA-CPACT, 1995. 58p.

16. SAS, INSTITUTE. Getting started with the SAS learning edition. Cary: SAS, 2002, 200p.

17. SOUTHWOOD, T. R. E. Ecological methods: with particular reference to the study of insect populations. 2ed. London: Chapman \& Hall, 1995. 524p.

18. SCOZ, L. P; BOTTON, M; GARCIA, S. M; PASTORI, L. P. Avaliação de atrativos alimentares e armadilhas para o monitoramento de Anastrepha fraterculus (Wiedemann, 1830) (Diptera: Tephritidae) na cultura do pessegueiro (Prunus persica (I.) Batsh). Idésia. Chile, v.24. n. 2, p. 7-13. 2006.

19. SUGAYAMA, R.L.; KOVALESKI, A.; LIEDO, P.; MALAVASI, A.Colonization of a new fruit crop by Anastrepha fraterculus (Diptera: Tephritidae) in Brazil: a demographic analysis. Environmental Entomology, Lanham, v. 27, p. 642-648, 1998.

20. TELLES, R, B; SILVA, M, N. Flutuação populacional de espécies de Anastrepha schiner (Diptera: Tephritidae) na região de Manaus, AM. Neotropical Entomology, Vacaria, v 34, n 5, p 733- 741. 2005.

21. ZUCCHI, R. A.Taxonomia. In: MALAVASI, A.; ZUCCHI, R. A. Moscas-das-frutas de importância econômica no Brasil: conhecimento básico e aplicado. Ribeirão Preto: Holos Editora, 2000, cap. 1, p.13-25.

22. ZUCCHI, R. A. Anastrepha species and their hosts plants. Fruit flies in Brazil (2008). Disponível em: <http:www.lef.esalq.usp.br/anstrepha/edita_infos.htm>. Acesso em: 27 set. 2011.

23. ZILLI, G; GARCIA, M. R. F. Análise faunística e flutuação populacional de moscas-das-frutas (Diptera, Tephritidae) em pomar de Citrus sinensis no Município de Chapecó, Santa Catarina. Biodiversidade Pampeana. Uruguaiana, v.8, n.1, p-39 -45. 2010.

Recebido em 05/03/2013

Aceito em 31/03/2015 